World Applied Sciences Journal 10 (11): 1392-400, 2010

ISSN 1818-4952

(C) IDOSI Publications, 2010

\title{
Robust Speed Sensorless Control of Doubly-fed Induction Machine Based on Input-output Feedback Linearization Control Using a Sliding-mode Observer
}

\author{
${ }^{1}$ A. Farrokh Payam and ${ }^{2}$ N. Hashemnia, A. Kashiha ${ }^{3}$ \\ ${ }^{1}$ School of Electrical and Computer Engineering, University of Tehran, Tehran, Iran \\ ${ }^{2}$ Department of Electrical Engineering, Sharif University of Technology, Tehran, Iran \\ ${ }^{3}$ Department of Electrical Engineering, Islamic Azad University, \\ Kermanshah Science and Research Branch, Kermanshah, Iran
}

\begin{abstract}
In this paper, a nonlinear controller is presented for Doubly-Fed Induction Machine (DFIM) drives. The nonlinear controller is designed based on the input-output feedback linearization control technique, combined with a sliding-mode observer, using the fifth order model of the doubly-fed induction machine in fixed stator $\mathrm{d}-\mathrm{q}$ axis reference frame with stator current and rotor flux components as state variables. The nonlinear controller can perfectly track the torque and flux reference signals in spite of stator and rotor resistance variations. In order to make the drive system capable of operating in the motoring and generating modes both below and above synchronous speed, two level SVM-PWM back-to-back voltage source inverters are employed in the rotor circuit. Computer simulation results obtained, confirm the effectiveness and validity of the proposed control approach.
\end{abstract}

Key words: Doubly fed induction machine . input-output feedback linearization . nonlinear controller . sliding-mode observer . rotor dc link voltage

\section{INTRODUCTION}

Doubly fed induction machines are very attractive to the high performance variable speed drive and generating applications $[1,2]$. In variable speed drive applications, the so-called slip power recovery scheme is a common practice where the power due to the rotor slip below/above synchronous speed is recovered to/supplied from the power source, resulting in a high efficiency variable speed system [3]. In variable speed generating applications, Doubly-fed Induction Generator (DFIG) wind turbines with converters rated at about $25-30 \%$ of the generator rating are becoming increasingly popular. DFIG-based wind turbines offer Variable Speed Constant Frequency (VSCF) operation, four-quadrant and decoupled active and reactive power capabilities, lower converter cost and reduced power loss compared to wind turbines using fixed speed squirrel cage induction generators or synchronous generators with full scale converters. In the DFIG system, stator is usually connected to the three-phase grid directly and rotor is fed by two back-to-back Pulse Width Modulation (PWM) or Space Vector Modulation (SVM) inverters (Fig. 1). This arrangement provides flexibility of operation in sub-synchronous and super-synchronous speeds in both generating and motoring modes. The power inverter needs only be rated for a fraction of the total output power, the fraction depending on the permissible sub-and supersynchronous speed range [4]. Therefore, it is possible to use a high-frequency switching PWM converter to achieve high performance, such as fast dynamic response, low harmonic distortion, high efficiency, etc., without cost penalty. However, a high-resolution rotor position sensor is generally needed for the proper operation of the doubly fed induction machine systems [3].

A drive system employing mechanical sensors has some drawbacks in terms of maintenance, cost, robustness and cabling between the sensor and the controller. The last problem is particularly crucial in applications such as wind power generation because there is a large physical separation between the generator (which is coupled to the turbine shaft through gears) and the power electronic equipment (which is at ground level) [4].

Sensorless systems for DFIGs have been previously published by several researchers. The method proposed in [5] uses the rotor voltages and currents to design a torque angle controller. The major

Corresponding Author: Dr. A. Farrokh Payam, School of Electrical and Computer Engineering, University of Tehran, Iran 


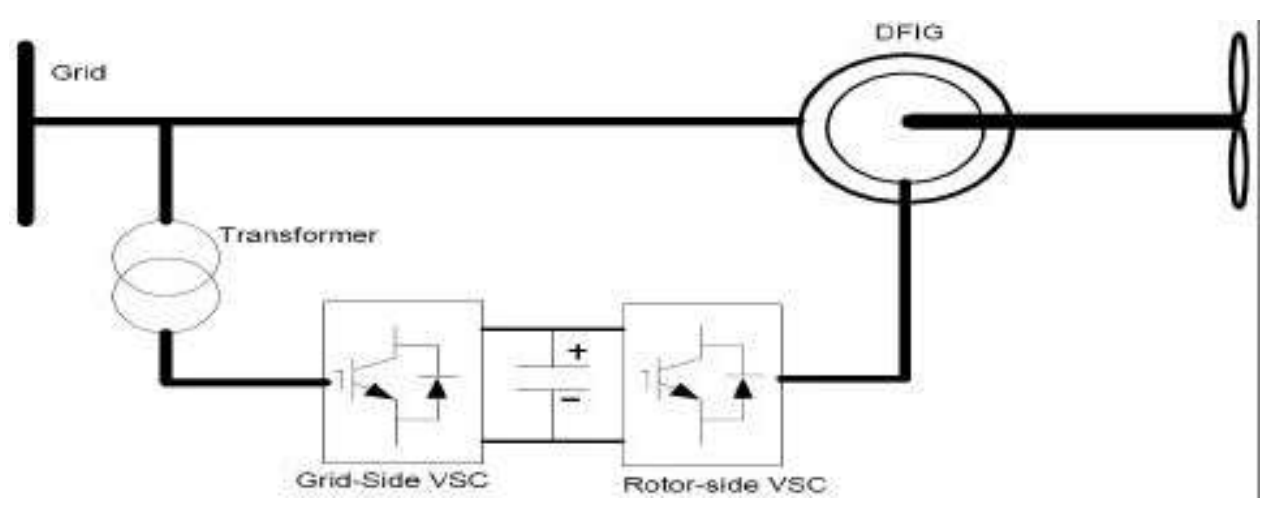

Fig. 1: A grid connected doubly-fed induction generator and its convertors

difficulty of this scheme is the method employed for computation of rotor flux. The integration of rotor voltage at or near synchronous speed is analogous to the integration of the stator voltage at or near zero speed. Hence, similar problems of integrator saturation, resulting in incorrect estimation of the rotor flux are inevitable. Use of this algorithm has to be restricted up to a certain minimum slip and operation through synchronous speed is not possible. On the other hand, although there are no $\mathrm{d}-\mathrm{q}$ transformations to need to know the rotor angle, rotor speed does have to be known if operation at MPPT mode is questioned.

Systems proposed in $[4,6,7]$ are based on open loop methods, where the estimated and measured rotor currents are compared in order to derive the rotor position and the speed is then obtained via differentiation. However, like any other open loop control system, problems of making the estimator robust to parameter variations and model uncertainties exist. Also, some noise is introduced in the speed signal via differentiation.

The principal theory of a vector controlled DFIM drive has been described in [8]. The structure of the system controller design in [8] is based on neglecting the voltage drop across the stator leakage impedance. Having made this assumption, a steady-state error is always expected. To solve the above problems, a few researchers have tried to apply nonlinear control approaches to DFIM drive system [9-14]. The nonlinear control techniques reported so far for DFIM drive are mostly parameter dependent or in other words are seriously affected by the machine parameters deviations.

Our purpose in this paper is to introduce a combined adaptive nonlinear controller for DFIM drive system for generating and motoring modes of operation both below and above the base speed. According to this method, based on input-output feedback linearization and sliding-mode observer, an ideal linear torque controller is designed for DFIM. The ideal input-output controller is capable of tracking a desired second order reference model. In this control system, the active and reactive power reference signals (injected to the stator circuit) are perfectly tracked in generating mode of operation. One may note that in the motoring mode of operation, the tracking signals are chosen to be the rotor speed and reactive power reference signal, injected to the stator circuit. The nonlinear controller is designed on the basis of DFIM fifth order model in a stationary $\mathrm{d}-\mathrm{q}$ axis reference frame, with rotor fluxes $\left(\psi_{\mathrm{dr}}, \psi_{\mathrm{qr}}\right)$ and stator currents $\left(\mathrm{i}_{\mathrm{ds}}, \mathrm{i}_{\mathrm{gs}}\right)$ as state variables. Considering a special synchronous reference frame with the d-axis coinciding with stator voltage space vector, the active and reactive power reference commands are converted into the norm of rotor flux and torque reference signals. However, in motoring mode of operation, the torque reference signal is generated by a conventional speed PI controller.

Moreover, to have a robust drive system and also in order to remove the rotor speed sensor, a slidingmode observer is designed that detects the rotor resistance and rotor speed online. In this observer, the estimation laws are derived based on the Lyapanouv stability theory and the rotor fluxes $\left(\psi_{\mathrm{dr}}, \psi_{\mathrm{gr}}\right)$ are calculated by using the stator and rotor real currents. Moreover, using the two level back-to-back SVM-PWM voltage source inverters in the rotor circuit, the proposed control method can be applied for motoring and generating modes of operation both below and above synchronous speed. In addition, the rotor dc link voltage is maintained constant based on the inputoutput linearization again, using a rotating reference frame with the $\mathrm{d}$-axis coinciding with the space voltage vector of the main ac supply. 


\section{DOUBLY-FED INDUCTION MACHINE MODEL}

Under assumption of linear magnetic circuit and balanced operating condition, the equivalent two-phase model of the symmetrical DFIM with stator connected to power grid, represented in fixed stator d-q reference frame is:

$$
\begin{aligned}
& \frac{\mathrm{di}_{\mathrm{ds}}}{\mathrm{dt}}=-\left(\frac{\mathrm{R}_{\mathrm{s}}}{\mathrm{L}_{\sigma}}+\frac{\mathrm{R}_{\mathrm{r}} \mathrm{L}_{\mathrm{m}}{ }^{2}}{\mathrm{~L}_{\mathrm{r}}{ }^{2} \mathrm{~L}_{\sigma}}\right) i_{\mathrm{ds}}+\frac{\mathrm{R}_{\mathrm{r}} \mathrm{L}_{\mathrm{m}}}{\mathrm{L}_{\mathrm{r}}{ }^{2} \mathrm{~L}_{\sigma}} \psi_{\mathrm{dr}} \\
& +\frac{\omega_{\mathrm{r}} \mathrm{L}_{\mathrm{m}}}{\mathrm{L}_{\mathrm{r}} \mathrm{L}_{\sigma}} \psi_{\mathrm{qr}}+\frac{\mathrm{u}_{\mathrm{ds}}}{\mathrm{L}_{\sigma}}-\frac{\mathrm{L}_{\mathrm{m}}}{\mathrm{L}_{\mathrm{r}} \mathrm{L}_{\sigma}} \mathrm{u}_{\mathrm{dr}} \\
& \frac{\mathrm{di}_{\mathrm{qs}}}{\mathrm{dt}}=-\left(\frac{\mathrm{R}_{\mathrm{s}}}{\mathrm{L}_{\sigma}}+\frac{\mathrm{R}_{\mathrm{r}} \mathrm{L}_{\mathrm{m}}^{2}}{\mathrm{~L}_{\mathrm{r}}{ }^{2} \mathrm{~L}_{\sigma}}\right) \mathrm{i}_{\mathrm{qs}}+\frac{\mathrm{R}_{\mathrm{r}} \mathrm{L}_{\mathrm{m}}}{\mathrm{L}_{\mathrm{r}}^{2} \mathrm{~L}_{\sigma}} \psi_{\mathrm{qr}} \\
& -\frac{\omega_{\mathrm{r}} \mathrm{L}_{\mathrm{m}}}{\mathrm{L}_{\mathrm{r}} \mathrm{L}_{\sigma}} \psi_{\mathrm{dr}}+\frac{\mathrm{u}_{\mathrm{qs}}}{\mathrm{L}_{\sigma}}-\frac{\mathrm{L}_{\mathrm{m}}}{\mathrm{L}_{\mathrm{r}} \mathrm{L}_{\sigma}} \mathrm{u}_{\mathrm{qr}} \\
& \frac{\mathrm{d} \psi_{\mathrm{dr}}}{\mathrm{dt}}=\frac{\mathrm{R}_{\mathrm{r}} \mathrm{L}_{\mathrm{m}}}{\mathrm{L}_{\mathrm{r}}} \mathrm{i}_{\mathrm{ds}}-\frac{\mathrm{R}_{\mathrm{r}}}{\mathrm{L}_{\mathrm{r}}} \psi_{\mathrm{dr}}-\omega_{\mathrm{r}} \psi_{\mathrm{qr}}+\mathrm{u}_{\mathrm{dr}} \\
& \frac{\mathrm{d} \psi_{\mathrm{qr}}}{\mathrm{dt}}=\frac{\mathrm{R}_{\mathrm{r}} \mathrm{L}_{\mathrm{m}}}{\mathrm{L}_{\mathrm{r}}} \mathrm{i}_{\mathrm{qs}}-\frac{\mathrm{R}_{\mathrm{r}}}{\mathrm{L}_{\mathrm{r}}} \psi_{\mathrm{qr}}+\omega_{\mathrm{r}} \psi_{\mathrm{dr}}+\mathrm{u}_{\mathrm{qr}}
\end{aligned}
$$

where, $\mathrm{i}_{\mathrm{s}}, \psi_{\mathrm{r}}, \mathrm{u}_{\mathrm{s}}, \mathrm{u}_{\mathrm{r}}, \mathrm{R}$ and $\mathrm{L}$ denote stator currents, rotor flux linkage, stator terminal voltage, rotor terminal voltage, resistance and inductance, respectively. The subscripts $\mathrm{s}$ and $\mathrm{r}$ stand for stator and rotor while subscripts $d$ and $q$ stand for vector components with respect to a fixed stator reference frame, respectively. $\omega_{\mathrm{r}}$ denotes the rotor electrical speed and $\mathrm{L}_{\mathrm{m}}$ is the mutual inductance.

$$
\mathrm{L}_{\sigma}=\mathrm{L}_{\mathrm{s}}\left(1-\left(\frac{\mathrm{L}_{\mathrm{m}}{ }^{2}}{\mathrm{~L}_{\mathrm{r}} \mathrm{L}_{\mathrm{s}}}\right)\right)
$$

is the redefined leakage inductance.

The generated torque of DFIM can be expressed in terms of stator current and rotor flux linkage components as

$$
\mathrm{T}_{\mathrm{e}}=\frac{3 \mathrm{P}}{2} \frac{\mathrm{L}_{\mathrm{m}}}{\mathrm{L}_{\mathrm{r}}}\left(\psi_{\mathrm{d} \mathrm{rqs}_{\mathrm{q}}}-\psi_{\mathrm{qr} \mathrm{ts}_{\mathrm{s}}}\right)
$$

Where $\mathrm{P}$ is the number of poles. The mechanical dynamic equation is given by

$$
\mathrm{J} \frac{\mathrm{d} \omega_{\mathrm{m}}}{\mathrm{dt}}+\mathrm{B} \omega_{\mathrm{m}}+\mathrm{T}_{\mathrm{L}}=\mathrm{T}_{\mathrm{e}}
$$

where $\mathrm{J}$ and $\mathrm{B}$ denote the moment of inertia of the motor and viscous friction coefficient, respectively, $T_{L}$ is the external load and $\omega_{\mathrm{m}}$ is the rotor mechanical speed $\left(\omega_{\mathrm{r}}=\left(\frac{\mathrm{P}}{2}\right) \omega_{\mathrm{m}}\right)$.

Let

$$
\mathrm{x}=\left[\begin{array}{llll}
\mathrm{i}_{\mathrm{ds}} & \mathrm{i}_{\mathrm{qs}} & \psi_{\mathrm{dr}} & \psi_{\mathrm{qr}}
\end{array}\right]^{\mathrm{T}}
$$

be the state vector and let the generated torque $T_{e}$ be the output y of the dynamic system (1), that is

$$
\mathrm{y}=\mathrm{T}_{\mathrm{e}}=\frac{3 \mathrm{P}}{2} \frac{\mathrm{L}_{\mathrm{m}}}{\mathrm{L}_{\mathrm{r}}}\left(\psi_{\mathrm{d} \mathrm{rqs}} \mathrm{i}_{\mathrm{q}}-\psi_{\mathrm{qr}} \mathrm{i}_{\mathrm{ds}}\right)
$$

It is well known that the torque control is very important for high-performance motion systems. However, from (1) and (5) we can view that the generated torque $T_{e}$ of DFIM is a nonlinear output with respect to state variables $\mathrm{x}$ of dynamic model (1), $\mathrm{i}_{\mathrm{ds}}, \mathrm{i}_{\mathrm{qs}}$, $\psi_{\mathrm{dr}}$ and $\psi_{\mathrm{qr}}$. Therefore, it is difficult to evaluate the torque response from (5) by the control input $\mathrm{u}_{\mathrm{dr}}$ and $\mathrm{u}_{\mathrm{qr}}$ designed for the model (1).

\section{INPUT-OUTPUT FEEDBACK CONTROL}

For the proposed nonlinear controller, a coordinate transformation is applied. Firstly, we write the model in (1) in a compact form as:

$$
\dot{\mathrm{x}}=\mathrm{f}(\mathrm{x})+\mathrm{g}_{1} \mathrm{u}_{\mathrm{dr}}+\mathrm{g}_{2} \mathrm{u}_{\mathrm{qr}}
$$

where $\mathrm{x}$ is defined in (4) and

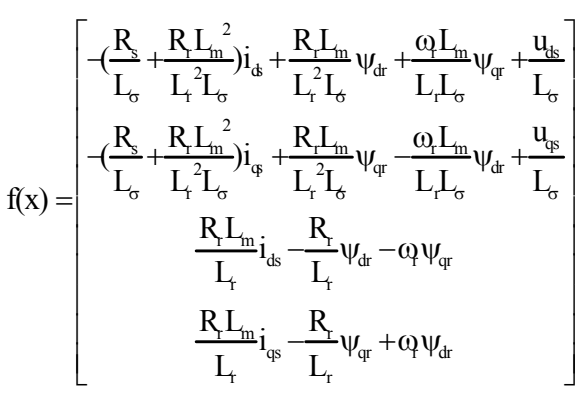

and

$$
\begin{aligned}
& \mathrm{g}_{1}=\left[\begin{array}{cccc}
-\frac{\mathrm{L}_{\mathrm{m}}}{\mathrm{L}_{\mathrm{r}} \mathrm{L}_{\sigma}} & 0 & 1 & 0
\end{array}\right]^{\mathrm{T}} \\
& \mathrm{g}_{2}=\left[\begin{array}{llll}
0 & -\frac{\mathrm{L}_{\mathrm{m}}}{\mathrm{L}_{\mathrm{r}} \mathrm{L}_{\sigma}} & 0 & 1
\end{array}\right]^{\mathrm{T}}
\end{aligned}
$$


At this stage, the generated torque $\mathrm{T}_{\mathrm{e}}$ and the squared modules of the rotor flux linkage $\left|\psi_{\mathrm{r}}\right|^{2}=\psi_{\mathrm{dr}}{ }^{2}+$ $\psi_{\mathrm{qr}}^{2}$ are chosen as the controlled outputs. Therefore, we consider

$$
\begin{aligned}
& \mathrm{h}_{1}(\mathrm{x})=\frac{3 \mathrm{P}}{2} \frac{\mathrm{L}_{\mathrm{m}}}{\mathrm{L}_{\mathrm{r}}}\left(\psi_{\mathrm{dr} \mathrm{qs}} \mathrm{i}_{\mathrm{gr}}-\psi_{\mathrm{gr}} \mathrm{i}_{\mathrm{ds}}\right) \\
& \mathrm{h}_{2}(\mathrm{x})=\psi_{\mathrm{dr}}{ }^{2}+\psi_{\mathrm{gr}}^{2}
\end{aligned}
$$

The following notation is used for the lie derivative of a function $\mathrm{h}(\mathrm{x}): \mathfrak{R}^{\mathrm{n}} \rightarrow \mathfrak{R}$ along a vector field $\mathrm{f}(\mathrm{x})=\left(\mathrm{f}_{1}(\mathrm{x}), \ldots, \mathrm{f}_{\mathrm{n}}(\mathrm{x})\right)$

$$
\mathrm{L}_{\mathrm{f}}(\mathrm{x})=\sum_{\mathrm{i}=1}^{\mathrm{n}} \frac{\partial \mathrm{h}}{\partial \mathrm{x}_{\mathrm{i}}} \mathrm{f}_{\mathrm{i}}(\mathrm{x})
$$

Iteratively, we define $\mathrm{L}_{\mathrm{f}}{ }^{\mathrm{i}} \mathrm{h}=\mathrm{L}_{\mathrm{f}}\left(\mathrm{L}_{\mathrm{f}}{ }^{\mathrm{i}-1} \mathrm{~h}\right)$.

Define the change of coordinates as

$$
\begin{aligned}
& z_{1}=h_{2}(x) \\
& z_{2}=h_{1}(x)
\end{aligned}
$$

Then, the dynamic model of DFIM is given in the new coordinates by

$$
\left[\begin{array}{c}
\dot{z}_{1} \\
\dot{z}_{2}
\end{array}\right]=\left[\begin{array}{c}
L_{\mathrm{f}} \mathrm{h}_{2} \\
\mathrm{~L}_{\mathrm{f}} \mathrm{h}_{1}
\end{array}\right]+\left[\begin{array}{cc}
\mathrm{L}_{\mathrm{g} 1} \mathrm{~h}_{2} & \mathrm{~L}_{\mathrm{g} 2} \mathrm{~h}_{2} \\
\mathrm{~L}_{\mathrm{g} 1} \mathrm{~h}_{1} & \mathrm{~L}_{\mathrm{g} 2} \mathrm{~h}_{1}
\end{array}\right]\left[\begin{array}{l}
\mathrm{u}_{\mathrm{dr}} \\
\mathrm{u}_{\mathrm{qr}}
\end{array}\right]
$$

where

$$
\begin{aligned}
& \mathrm{L}_{\mathrm{r}} \mathrm{h}_{2}=2 \frac{\mathrm{R}_{\mathrm{r}} \mathrm{L}_{\mathrm{m}}}{\mathrm{L}_{\mathrm{r}}}\left(\mathrm{i}_{\mathrm{d}} \psi_{\mathrm{qr}}-\mathrm{i}_{\mathrm{qs}} \psi_{\mathrm{d}}\right)-2 \frac{\mathrm{R}_{\mathrm{r}}}{\mathrm{L}_{\mathrm{r}}}\left(\psi_{\mathrm{dr}}^{2}+\psi_{\mathrm{qr}}^{2}\right) \\
& \mathrm{L}_{\mathrm{r}} \mathrm{h}_{1}=\frac{3 \mathrm{P}}{2} \frac{\mathrm{L}_{\mathrm{m}}}{\mathrm{L}_{\mathrm{r}}} \times
\end{aligned}
$$

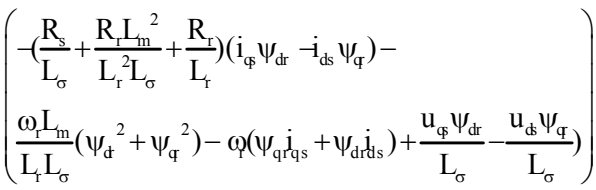

$$
\begin{aligned}
& \mathrm{L}_{\mathrm{g} 1} \mathrm{~h}_{2}=2 \psi_{\mathrm{dr}} \\
& \mathrm{L}_{\mathrm{g} 2} \mathrm{~h}_{2}=2 \psi_{\mathrm{qr}} \\
& \mathrm{L}_{\mathrm{g} 1} \mathrm{~h}_{1}=\frac{3 \mathrm{P}}{2} \frac{\mathrm{L}_{\mathrm{m}}}{\mathrm{L}_{\mathrm{r}}}\left(\mathrm{i}_{\mathrm{qs}}+\frac{\mathrm{L}_{\mathrm{m}}}{\mathrm{L}_{\mathrm{r}} \mathrm{L}_{\mathrm{\sigma}}} \psi_{\mathrm{qr}}\right) \\
& \mathrm{L}_{\mathrm{g} 2} \mathrm{~h}_{1}=-\frac{3 \mathrm{P}}{2} \frac{\mathrm{L}_{\mathrm{m}}}{\mathrm{L}_{\mathrm{r}}}\left(\mathrm{i}_{\mathrm{ds}}+\frac{\mathrm{L}_{\mathrm{m}}}{\mathrm{L}_{\mathrm{r}} \mathrm{L}_{\sigma}} \psi_{\mathrm{dr}}\right)
\end{aligned}
$$

Furthermore, a nonlinear state feedback method is employed in order to decouple the control inputs. We construct the new control inputs as follows

$$
\left[\begin{array}{l}
\hat{\mathrm{u}}_{\mathrm{dr}} \\
\hat{\mathrm{u}}_{\mathrm{ur}}
\end{array}\right]=\left[\begin{array}{l}
\mathrm{L}_{\mathrm{g} 1} \mathrm{~h}_{2}(\mathrm{x}) \mathrm{u}_{\mathrm{dr}}+\mathrm{L}_{\mathrm{g} 2} \mathrm{~h}_{2}(\mathrm{x}) \mathrm{u}_{\mathrm{qr}} \\
\mathrm{L}_{\mathrm{g}} \mathrm{h}_{1}(\mathrm{x}) \mathrm{u}_{\mathrm{dr}}+\mathrm{L}_{\mathrm{g} 2} \mathrm{~h}_{2}(\mathrm{x}) \mathrm{u}_{\mathrm{qr}}
\end{array}\right]
$$

Then, the system (12) becomes

$$
\left[\begin{array}{l}
\dot{\mathrm{z}}_{1} \\
\dot{\mathrm{z}}_{2}
\end{array}\right]=\left[\begin{array}{l}
\mathrm{L}_{\mathrm{f}} \mathrm{h}_{2}(\mathrm{x}) \\
\mathrm{L}_{\mathrm{h}} \mathrm{h}(\mathrm{x})
\end{array}\right]+\left[\begin{array}{ll}
1 & 0 \\
0 & 1
\end{array}\right]\left[\begin{array}{l}
\hat{\mathrm{u}}_{\mathrm{dr}} \\
\hat{\mathrm{u}}_{\mathrm{qr}}
\end{array}\right]
$$

Define the system errors as

$$
\begin{aligned}
& \mathrm{e}_{\mathrm{z} 1}=\mathrm{z}_{1}-\psi_{\mathrm{r}}^{* 2} \\
& \mathrm{e}_{\mathrm{z} 2}=\mathrm{z}_{2}-\mathrm{T}_{\mathrm{e}}^{*}
\end{aligned}
$$

Derivation of the error model (16) gives

$$
\begin{aligned}
\dot{\mathrm{e}}_{\mathrm{zl}} & =\mathrm{L}_{\mathrm{f}} \mathrm{h}_{2}(\mathrm{x})+\overline{\mathrm{u}}_{\mathrm{dr}}+\phi_{1} \mathrm{~d}_{\mathrm{l}}(\mathrm{x}) \\
\dot{\mathrm{e}}_{\mathrm{z} 2} & =\mathrm{L}_{\mathrm{f}} \mathrm{h}_{1}(\mathrm{x})+\overline{\mathrm{u}}_{\mathrm{qr}}+\phi_{2} \mathrm{~d}_{2}(\mathrm{x}) \\
\dot{\mathrm{e}}_{\mathrm{z}} & =\mathrm{A}(\mathrm{x})+\mathrm{B}(\mathrm{x}) \overline{\mathrm{U}}
\end{aligned}
$$

It is obvious that the controllers $\overline{\mathrm{u}}_{\mathrm{dr}}$ and $\overline{\mathrm{u}}_{\mathrm{qr}}$ are decoupled with respect to two dynamic models, $\left[\mathrm{e}_{\mathrm{zl}}, \mathrm{e}_{22}\right]$. According to the above equations, the input-output control for the first equation of (17) is designed as

$$
\overline{\mathrm{u}}_{\mathrm{dr}}=-\mathrm{L}_{\mathrm{f}} \mathrm{h}(\mathrm{x})-\phi_{1} \mathrm{~d}_{\mathrm{l}}(\mathrm{x})-\mathrm{k}_{\mathrm{l}} \mathrm{e}_{\mathrm{zl}}
$$

where $\mathrm{k}_{1}>0$. Similarly, the input-output feedback control for the second dynamic equation of (17) is designed as follows

$$
\overline{\mathrm{u}}_{\mathrm{qr}}=-\mathrm{L}_{\mathrm{f}} \mathrm{h}_{1}(\mathrm{x})-\phi_{2} \mathrm{~d}_{2}(\mathrm{x})-\mathrm{k}_{2} \mathrm{e}_{\mathrm{z} 2}
$$

where $\mathrm{k}_{2}$ is the positive constant feedback gain.

Theorem 2: Using the controller described by (18-19), the controlled torque and flux amplitude of the DFIM are stable.

Proof: The proof is obtained by choosing the following Lyapanov function

$$
\mathrm{V}_{1}=\frac{1}{2}\left[\mathrm{e}_{\mathrm{zl}}^{2}+\mathrm{e}_{\mathrm{z} 2}^{2}\right]
$$

Taking the derivative of (20) with respect to time and then substituting (17) into this derivative, we can obtain 


$$
\begin{aligned}
\dot{\mathrm{V}}_{1}= & \mathrm{e}_{\mathrm{z} 1}\left[\mathrm{~L}_{\mathrm{f}(\mathrm{x})} \mathrm{h}_{2}(\mathrm{x})+\overline{\mathrm{u}}_{\mathrm{dr}}+\phi_{1} \mathrm{~d}_{1}(\mathrm{x})\right]+ \\
& \mathrm{e}_{\mathrm{z} 2}\left[\mathrm{~L}_{\mathrm{f}(\mathrm{x})} \mathrm{h}_{1}(\mathrm{x})+\overline{\mathrm{u}}_{\mathrm{qr}}+\phi_{2} \mathrm{~d}_{2}(\mathrm{x})\right]
\end{aligned}
$$

Substituting (18), (19) into equation (21), gives

$$
\mathrm{V}_{1}=-\mathrm{k}_{1} \mathrm{e}_{\mathrm{z} 1}^{2}-\mathrm{k}_{2} \mathrm{e}_{\mathrm{z} 2}^{2} \leq 0
$$

Define the following equation

$$
\mathrm{M}(\mathrm{t})=\mathrm{k}_{1} \mathrm{e}_{\mathrm{z} 1}{ }^{2}+\mathrm{k}_{2} \mathrm{e}_{\mathrm{z} 2}{ }^{2} \geq 0
$$

and the following function

$$
\mathrm{V}_{1}(\mathrm{t})=\mathrm{V}_{1}(\mathrm{e}(0), \phi(0))+\int_{0}^{\mathrm{t}} \dot{\mathrm{V}}_{1}(\partial) \mathrm{d} \tau=\mathrm{V}_{\mathrm{l}}(\mathrm{e}(0), \phi(0))-\int_{0}^{\mathrm{t}} \mathrm{M}(\tau) \mathrm{d} \tau
$$

where $\mathrm{e}=\left[\mathrm{e}_{\mathrm{zl}}, \mathrm{e}_{\mathrm{z} 2}\right]^{\mathrm{T}}$. From the definition of the above Lyapanouv function, $V_{1}(t) \geq 0$. The following result can be deduced

$$
\lim _{\mathrm{t} \rightarrow \infty} \int_{0}^{\mathrm{t}} \mathrm{M}(\tau) \mathrm{d} \tau \leq \mathrm{V}_{\mathrm{l}}(\mathrm{e}(0), \phi(0))<\infty
$$

Based on the Barbalat's Lemma [15], we can obtain

$$
\mathrm{M}(\mathrm{t}) \rightarrow 0 \text { as } \mathrm{t} \rightarrow \infty
$$

That is, $e_{11}$ and $e_{22}$ will converge to zero as $t \rightarrow \infty$. Therefore, the proposed controller is stable and robust.

\section{DESIGN OF ROTOR FLUX OBSERVER}

Choosing stator current and rotor flux as state variables, the space vector model of DFIM in the stator reference frame can be expressed by:

$$
\begin{gathered}
\frac{d i_{s}}{d t}=-\left(\gamma_{1}+j \omega_{0}\right) i_{s}+\beta(\alpha-j \omega) \psi_{r}+\frac{u_{s}}{\sigma}-\beta u_{r} \\
\frac{d \psi_{r}}{d t}=\alpha L_{m} i_{s}-\left(\alpha-j\left(\omega_{0}-\omega\right)\right) \psi_{r}+u_{r}
\end{gathered}
$$

The adaptive rotor flux observer is introduced as:

$$
\left.\frac{d \hat{i}_{s}}{d t}=-\left(\hat{\gamma}_{1}+j \omega_{0}\right) i_{s}+\beta \hat{\alpha}-j \hat{\omega}\right) \hat{\psi}_{r}+\frac{u_{s}}{\sigma}-\beta u_{r}-K \operatorname{sgn}(\tilde{s})
$$

Where

$$
\hat{\alpha}=\alpha_{\mathrm{n}}+\Delta \hat{\alpha}, \hat{\gamma}_{1}=\left(\frac{\mathrm{R}_{\mathrm{s}}}{\sigma}+\hat{\alpha} \mathrm{L}_{\mathrm{m}} \beta\right)
$$

In order to develop the adaptation laws, it is assumed that the motor speed and rotor and stator resistances are unknown but constant parameters. Therefore, from (27) and (28), the observer error dynamic are expressed by

$$
\left.\frac{d \tilde{i}_{s}}{d t}=-\left(\tilde{\gamma}_{1}\right) i_{s}+\beta(\tilde{\alpha}-j \tilde{\omega}) \hat{\psi}_{\mathrm{r}}+\beta(\alpha-j \omega) \tilde{\psi}_{\mathrm{r}}-\mathrm{K} \operatorname{sgn} \tilde{(\mathrm{i}}\right)
$$

$$
\frac{\mathrm{d} \tilde{\psi}_{\mathrm{r}}}{\mathrm{dt}}=\tilde{\alpha} \mathrm{L}_{\mathrm{m}} \mathrm{i}_{\mathrm{s}}-(\tilde{\alpha}+\mathrm{j} \tilde{\omega}) \hat{\psi}_{\mathrm{r}}-\left(\alpha-\mathrm{j}\left(\omega_{0}-\omega\right)\right) \tilde{\psi}_{\mathrm{r}}
$$

where:

$$
\begin{aligned}
& \tilde{i}_{\mathrm{s}}=\hat{\mathrm{i}}_{\mathrm{s}}-\mathrm{i}_{\mathrm{s}}, \tilde{\psi}_{\mathrm{r}}=\hat{\psi}_{\mathrm{r}}-\psi_{\mathrm{r}}, \tilde{\alpha}=\hat{\alpha}-\alpha, \\
& \tilde{\gamma}_{1}=\hat{\gamma}_{1}-\gamma_{1}, \tilde{\omega}=\hat{\omega}-\omega
\end{aligned}
$$

Choosing the following function as Lyapunov candidate

$$
\mathrm{V}=\frac{1}{2}\left(\tilde{\psi}_{\mathrm{r}}^{\mathrm{T}} \tilde{\psi}_{\mathrm{r}}+\frac{1}{\mathrm{c}_{\omega}} \tilde{\omega}^{2}+\frac{1}{\mathrm{c}_{\alpha}} \tilde{\alpha}^{2}\right)
$$

derivating $\mathrm{V}$ with respect to time gives

$$
\begin{aligned}
\dot{\mathrm{V}}= & -\alpha \tilde{\psi}_{\mathrm{r}}^{\mathrm{T}} \tilde{\psi}_{\mathrm{r}}+\tilde{\omega}\left(\frac{1}{\mathrm{c}_{\omega}} \dot{\tilde{\omega}}-\left(\mathrm{j} \hat{\psi}_{\mathrm{r}}\right)^{\mathrm{T}} \tilde{\psi}_{\mathrm{r}}\right) \\
& +\tilde{\alpha}\left(\frac{1}{\mathrm{c}_{\alpha}} \dot{\tilde{\alpha}}-\left(\hat{\psi}_{\mathrm{r}}-\mathrm{L}_{\mathrm{m}} \mathrm{i}_{\mathrm{s}}\right)^{\mathrm{T}} \tilde{\psi}_{\mathrm{r}}\right)
\end{aligned}
$$

As a result, the adaptation laws are obtained from (31) as:

$$
\begin{gathered}
\dot{\tilde{\omega}}=\mathrm{c}_{\mathrm{w}}\left(\mathrm{j} \hat{\psi}_{\mathrm{r}}\right)^{\mathrm{T}} \tilde{\psi}_{\mathrm{r}} \\
\dot{\tilde{\alpha}}=\mathrm{c}_{\alpha}\left(\hat{\psi}_{\mathrm{r}}-\mathrm{L}_{\mathrm{m} s} \mathrm{i}_{\mathrm{s}}\right)^{\mathrm{T}} \tilde{\psi}_{\mathrm{r}}
\end{gathered}
$$

\section{ACTIVE AND REACTIVE STATOR POWER CONTROL}

For both the motoring and generation modes of operation of DFIM, it is desired to regulate the stator active and reactive powers, whose references are $\mathrm{P}_{\mathrm{s}}^{*}$ and $\mathrm{Q}_{\mathrm{s}}^{*}$ respectively. Considering a synchronous $\mathrm{d}-\mathrm{q}$ axis rotating reference frame with the $d$ axis coinciding 


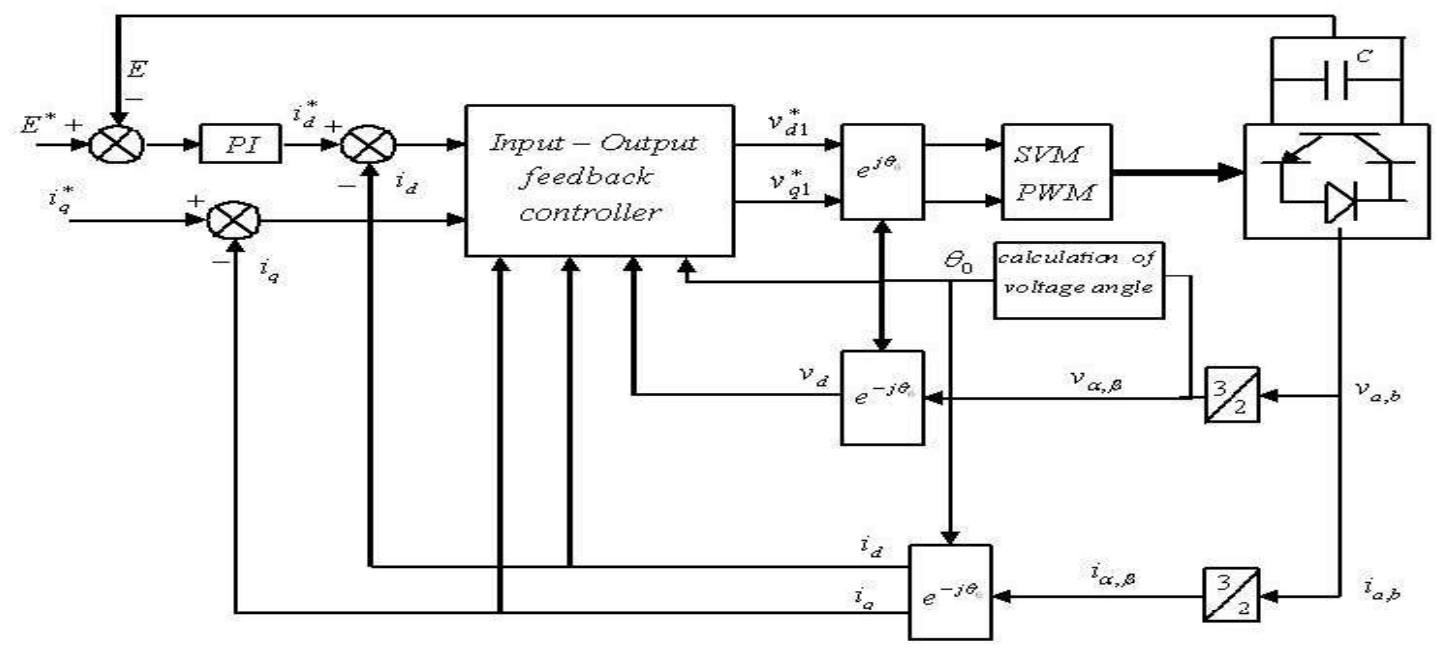

Fig. 1: DC link voltage controller [17]

with space voltage vector for the main ac supply, it is shown in reference [16] that:

$$
\begin{aligned}
& \mathrm{i}_{\mathrm{d}}^{*}=\frac{3}{2} \frac{\mathrm{P}_{\mathrm{s}}^{*}}{\mathrm{U}} \\
& \mathrm{i}_{\mathrm{q}}^{*}=\frac{3}{2} \frac{\mathrm{Q}_{\mathrm{s}}^{*}}{\mathrm{U}}
\end{aligned}
$$

In addition, the rotor flux references can be obtained as:

$$
\begin{gathered}
\psi_{\mathrm{d}}^{*}=\frac{1}{\beta \omega_{0}}\left(-\frac{\mathrm{R}_{\mathrm{s}}}{\sigma} \mathrm{i}_{\mathrm{q}}^{*}-\omega_{0} \mathrm{i}_{\mathrm{d}}^{*}\right) \\
\psi_{\mathrm{q}}^{*}=\frac{1}{\beta \omega_{0}}\left(\frac{\mathrm{R}_{\mathrm{s}}}{\sigma} \mathrm{i}_{\mathrm{d}}^{*}-\omega_{0} \mathrm{i}_{\mathrm{q}}^{*}-\frac{1}{\sigma} \mathrm{U}\right)
\end{gathered}
$$

So, rotor flux and torque references are calculated as below

$$
\begin{gathered}
\psi_{\mathrm{r}}^{*}=\sqrt{\left(\psi_{\mathrm{d}}^{* 2}+\psi_{\mathrm{q}}^{* 2}\right)} \\
\mathrm{T}_{\mathrm{e}}^{*}=\mu\left(\psi_{\mathrm{d}}^{*} \mathrm{i}_{\mathrm{q}}^{*}-\psi_{\mathrm{q}}^{*} \mathrm{i}_{\mathrm{d}}^{*}\right)
\end{gathered}
$$

\section{STABILIZATION OF ROTOR DC LINK VOLTAGE}

In this paper, the rotor dc link voltage is maintained constant on the basis of input-output feedback linearization technique. The control strategy is shown in Fig. 1 [17].

\section{SYSTEM SIMULATION}

A $\mathrm{C}^{++}$computer program was developed to model this system on P.C.

The overall block diagram of the proposed controller is shown in Fig. 2.

In this program, a static runge-kutta fourth order method is used to solve the system equations. The effectiveness and validity of the proposed approach is tested on a three-phase $5-\mathrm{KW}, 380 \mathrm{~V}$, six-pole, $50 \mathrm{~Hz}$ DFIM drive [10] by simulation.

In order to investigate system robustness to parameter variations, all simulations have been performed for $R_{r}=2 R_{m}$, where $R_{m}$ is the nominal rotor resistance.

Figure 3 shows the drive system performance in generating mode of operation above the synchronous speed. Active and reactive power references and torque and flux references are shown in Fig. 3. The rotor has been kept at a constant speed of $\omega_{\mathrm{r}}=375(\mathrm{rad} / \mathrm{sec})$.

Figure 4 shows the system performance in the motoring mode of operation below and above synchronous speed.

In all modes of operation, the torque and rotor reference flux signals are obtained based on the desired active and reactive power reference profiles which are injected to the stator from the main ac supply.

For the sake of comparison, the method in this paper is compared with the one in [18], where a direct active and reactive power control strategy for DFIG has been used. This method was first used in three-phase PWM rectifiers [19], where the converter switching states were selected from an optimal switching table 


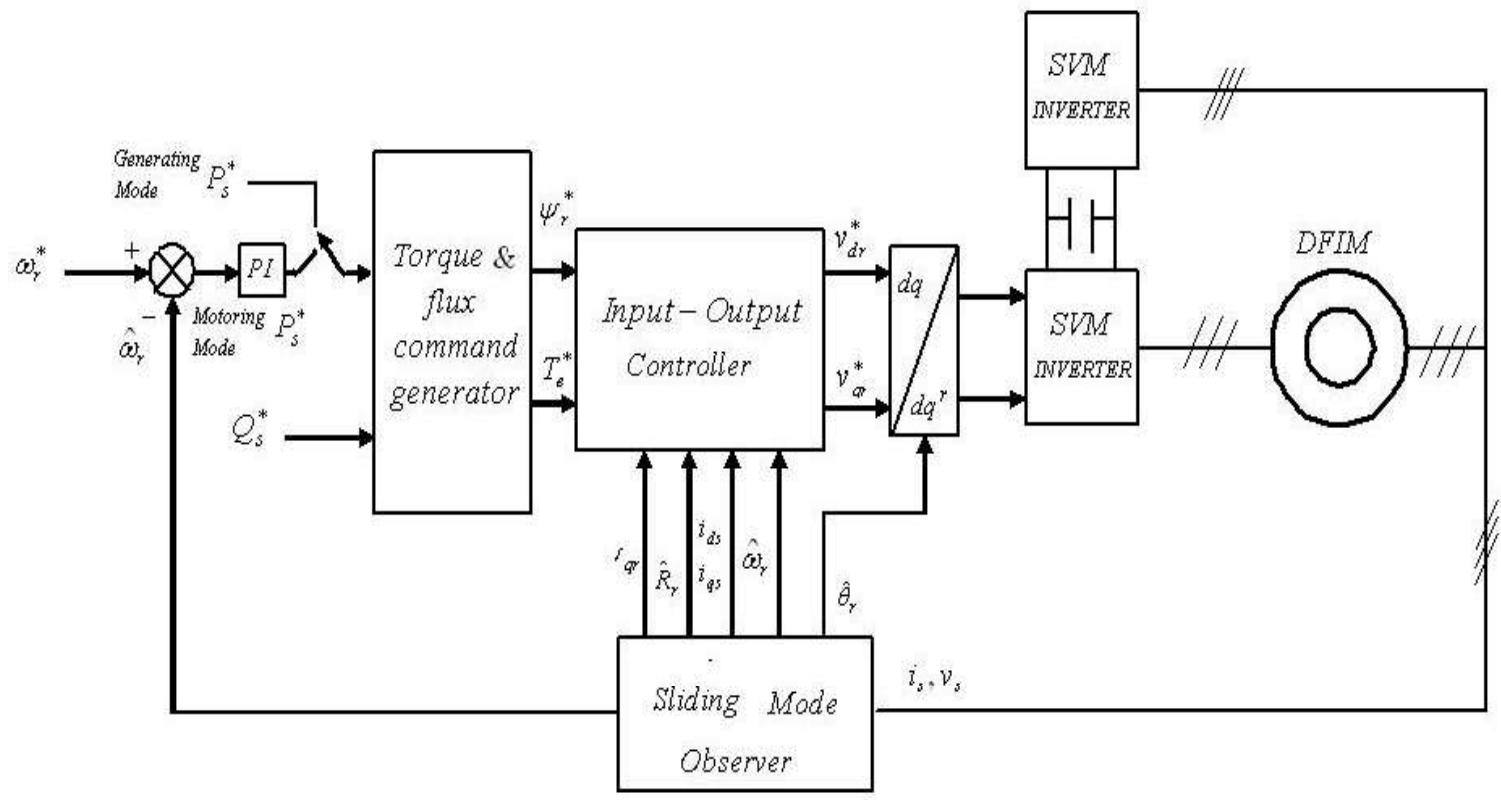

Fig. 2: Block diagram of proposed controller
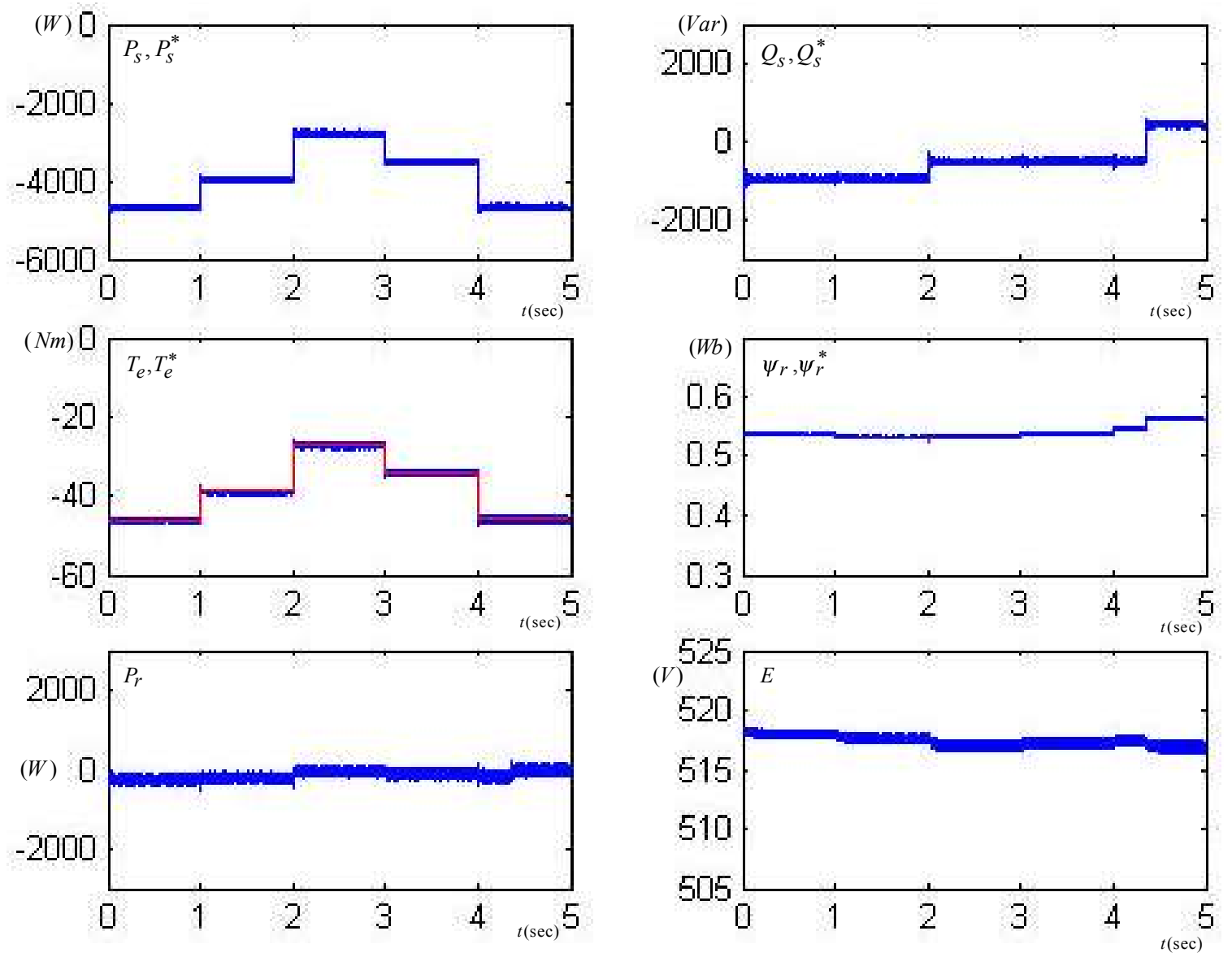

Fig. 3: Simulation results for generating mode above synchronous speed 

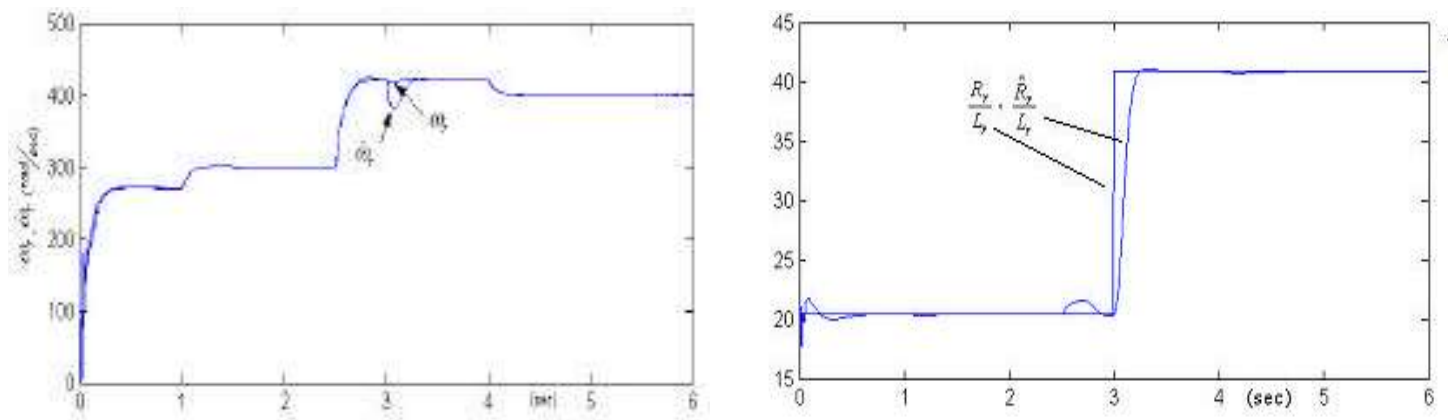

Fig. 4: Simulation results for motoring mode of operation
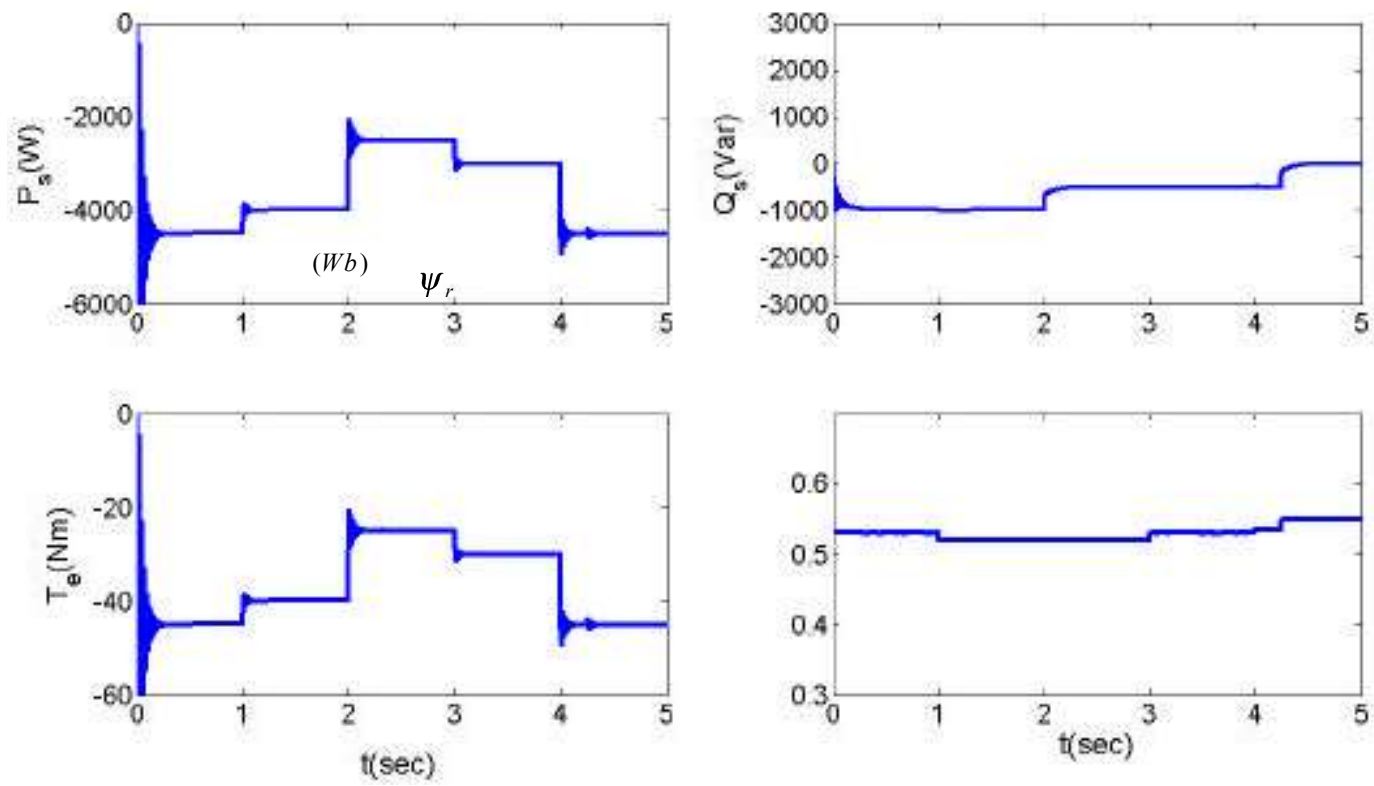

Fig. 5: Simulation results for generating mode above synchronous speed using the method in [18]

based on the instantaneous errors between the reference and estimated values of active and reactive power and the angular position of the estimated converter terminal voltage vector. In [18] two three-level hysteresis comparators are used to generate the respective active and reactive power states. Based on these states and also the position of stator flux in the rotor reference frame, optimal rotor voltage vector is selected. Stator flux is first estimated in the stationary reference frame using the following equation:

$$
\Psi_{\mathrm{s}}^{\mathrm{s}}=\int\left(\mathrm{V}_{\mathrm{s}}^{\mathrm{s}}-\mathrm{R}_{\mathrm{s}} \mathrm{g} \mathrm{dt}\right.
$$

Since the amplitude and frequency of stator voltage is relatively fixed, an accurate estimation of stator flux is provided using the above relation. It is then transformed to the rotor reference frame using rotor angular position.
The presence of rotor resistance is a critical problem in this method, since the impact of rotor resistance on rotor flux (as in the following relation) has been neglected:

$$
\frac{d \psi_{r}^{r}}{d t}=V_{r}^{r}-R_{r} I_{r}^{r}
$$

Therefore, the same problems in stator flux estimation at low speed can arise in rotor flux estimation near synchronous speed and for high rotor resistance machines.

The method in [18] has been simulated for generating mode above synchronous speed and the results are depicted in Fig. 5. In comparison to Fig. 3, it is observed that there are several bad overshoots in active and reactive powers in the method in [18] while 
no overshoot is visible in the proposed method. Moreover, the proposed model is more robust to parameter variations. Finally, there is better decoupling between active and reactive powers in the proposed method.

\section{CONCLUSION}

In this paper, an adaptive nonlinear controller has been introduced for DFIM drives. The proposed controller is designed based on input-output feedback linearization combined with Sliding-Mode observer. The proposed control approach has been tested for both the motoring and generating modes of operation both bellow and above synchronous speed, using the twolevel SVM-PWM back-to-back voltage source inverters in the rotor circuit. Computer simulation results confirm the validity and effectiveness of the proposed control approach.

\section{REFERENCES}

1. Xu, L. and Y. Tang, 1992. A novel variable speed constant frequency wind power generating system using doubly-excited brushless reluctance machine. Presented at the IEEE Ind. Applications. Soc. Annual. Meeting, Houston, TX.

2. Doradla, S.R., S. Shakravorty and K.E. Hole, 1988. A new slip recovery scheme with improved supply power factor. IEEE Trans. Power Electron., Vol: 2 (2).

3. Xu, L. and W. Cheng, 1995. Torque and Reactive Power Control of a Doubly Fed Induction Machine by Position Sensorless Scheme. IEEE Trans on Industrial Applications, 31 (3): 636-642.

4. Datta, R. and V. Ranganathan, 2002. Variable-Speed Wind Power Generation Using a Doubly Fed Wound Rotor Induction Machine: A Comparison with Alternative Schemes. IEEE Power Engineering Review, 22 (7): 52-55.

5. Leonhard, W., 2001. Control of Electrical Drives. Springer, pp: 400-418.

6. Abolhassani, M., P. Niazi, H. Toliyat and P. Enjeti, 2003. A sensorless integrated doubly-fed electric alternator/active filter (IDEA) for variable speed wind energy system. In Proc. 38th IAS Annu. Meeting, 1: 507-514.

7. Morel, L., H. Godfroid, A. Mirzaian and J.M. Kauffman, 1998. Double fed induction machine, Converter optimization and field oriented control without position sensor. Proc. Inst. Elect. Eng, 145 (4): 360-368.
8. Hopfensperger, B., J. Atkinson and R.A. Lakin, 2000. Stator-flux-oriented control of a doubly-fed induction machine with and without position encoder. IEE Proc. Electr. Power Appl, 147 (4): 241-250.

9. Peresada, S., A. Tilli and A. Tonielli, 1998. Robust active-reactive power control of a doubly-fed induction generator. In Proc. IEEE-IECON'98, Aachen, Germany, pp: 1621-1625.

10. Peresada, S., A. Tilli and A. Tonielli, 2003. Indirect stator flux-oriented output feedback control of a doubly fed induction machine. IEEE Trans. Contr Sys, 11 (6): 875-888.

11. Patin, N., A. Nassani, E. Monmasson and J.-P. Louis, 2007. Sliding mode control of a doubly-fed induction generator. European Conference on Power Electronics and Applications, pp: 1-9.

12. Vidal, P., P. David and F. Bonnet, 2008. Mixed control strategy of a doubly fed induction machine. 90 (5): 337-346.

13. Lan, P.N., N.P. Quang and P. Buechner, 2006. A non-linear control algorithm for improving performance of wind generator using doubly-fed induction generator. Proceeding of European Wind Energy Conference.

14. Li, D.D., 2006. Decoupled Power Control of Wind Turbine Based on Doubly-Fed Induction Generator. IEEE Conf on Industrial Electronics and Applications, pp: 1-5.

15. Jeffery T. Spooner, Manfred Maggiore, Raul Ordonez and Kevin M. Passino, Stable Adaptive Control And Estimation For Nonlinear Systems. John Wiley and Sons, Inc. NewYork.

16. Peresada, S., A. Tilli and A. Tonielli, 1999. Robust Output Feedback Control of a Doubly Fed Induction Machine. Proc IEEE, pp: 1348-1354.

17. Soltani, J. and A. Farrokh Payam, 2006. A Robust Adaptive Sliding-Mode Controller for Slip Power Recovery Induction Machine Drives. Proc. IEEE/IPEMC 2006.

18. Lie $\mathrm{Xu}$ and $\mathrm{P}$. Cartwright, 2006. Direct active and reactive power control of DFIG for wind energy generation. IEEE Trans on Energy Conversion, 21 (3): 750-758.

19. Noguchi, T., H. Tomiki, S. Kondo and I. Takahashi, 1998. Direct power control of PWM converter without power-source voltage sensors. IEEE Trans. Ind. Appl., 34 (3): 473-479. 